\title{
Morphologic and Chemical Properties of PMMA/ATH Layers with Enhanced Abrasion Resistance Realised by Cold Plasma Spraying at Atmospheric Pressure
}

\author{
L. Wallenhorst $\left(\mathbb{D},{ }^{1,2}\right.$ R. Rerich, ${ }^{1}$ M. Vovk $\left(\mathbb{D},{ }^{3}\right.$ S. Dahle $\left(\mathbb{D},{ }^{4}\right.$ H. Militz, ${ }^{2}$ \\ G. Ohms, ${ }^{1}$ and W. Viöl ${ }^{1,5}$ \\ ${ }^{1}$ Laboratory of Laser and Plasma Technologies, University of Applied Sciences and Arts, Von-Ossietzky-Straße 99, \\ 37085 Göttingen, Germany \\ ${ }^{2}$ Wood Biology and Wood Products, Faculty of Forest Sciences, University of Göttingen, Büsgenweg 4, 37075 Göttingen, Germany \\ ${ }^{3}$ Biotechnical Faculty, University of Ljubljana, Jamnikarjeva 101, SI-1000 Ljubljana, Slovenia \\ ${ }^{4}$ Institute of Energy Research and Physical Technologies, Clausthal University of Technology, Leibnizstraße 4, \\ 38678 Clausthal-Zellerfeld, Germany \\ ${ }^{5}$ Fraunhofer Institute for Surface Engineering and Thin Films, Application Center for Plasma and Photonics, \\ Von-Ossietzky-Str. 100, 37085 Göttingen, Germany
}

Correspondence should be addressed to L. Wallenhorst; lena.wallenhorst@hawk-hhg.de

Received 12 October 2017; Accepted 24 December 2017; Published 1 February 2018

Academic Editor: Jörg Fink

Copyright (C) 2018 L. Wallenhorst et al. This is an open access article distributed under the Creative Commons Attribution License, which permits unrestricted use, distribution, and reproduction in any medium, provided the original work is properly cited.

\begin{abstract}
This study investigated the morphologic and chemical properties of coatings based on PMMA/ATH powder and deposited by cold plasma spraying on wood and glass. Since the deposition of pure PMMA/ATH powder with air as process gas yielded coatings with insufficient abrasion resistance, two modifications of the basic process were investigated. Previous studies showed that replacing air as process gas with forming gas did not enhance the abrasion resistance, but the addition of a phenol-formaldehyde resin (PF) succeeded in stabilising the particle coatings. In this work, results from morphologic and chemical analysis suggested an encasement of the PMMA/ATH particles by plasma-modified PF and thus a fusion of individual particles, explaining the enhanced bonding. Moreover, adhesion tests confirmed an outstanding bonding between the coating and wood as well as glass, which is assumed to result from interactions between the PF's hydroxyl groups and functional groups on the substrates' surfaces. Studies on the wettability revealed a hydrophobic character of such coatings, therefore generally indicating a possible application, for example, to reduce water uptake by wooden materials.
\end{abstract}

\section{Introduction}

Poly(methyl methacrylate), PMMA, that is reinforced with aluminium trihydrate $\left(\mathrm{Al}(\mathrm{OH})_{3}\right.$ or $\left.\mathrm{ATH}\right)$ and other additives for achieving specific properties is classified as solid surface material [1], with characteristics meeting the requirements of the performance standard ANSI/ICPA SS-1-2001. The PMMA/ATH composite, as it is abbreviated, was developed and described by Duggins and coworkers [2, 3]. In general, the composites contain about 50 to 70 wt.\% of ATH filler and about 30 to 50 wt.\% of PMMA resin. Because of this composition, machining of PMMA/ATH composite is very similar to machining of wood, but PMMA/ATH can additionally be thermoformed [4-7], similar to thermoplastics. Unlike wood, though, it exhibits a high moisture resistance along with good chemical and UV resistance. These properties make PMMA/ATH composites widely useable as working surfaces and claddings for indoor and outdoor applications. Because of the possibility of gaining antimicrobial characteristics [8], this material is also of use in laboratories, hospitals, and public places.

The production of workpieces, however, includes trimming and sanding of the PMMA/ATH sheets, leading to about $20 \%$ of the overall material produced becoming 
postindustrial waste. These cut-offs and waste powder amount to approximately 1000 tons of PMMA/ATH waste every year in Slovenia alone. Different methods of recycling this particular waste have already been considered [9-15], but none of them has yet provided a simple, sustainable, and cost-effective solution. In the past few years, some researches have aimed to develop new methods of recycling or reusing PMMA/ATH waste and by-products [1619]. The common idea throughout this research was to connect the PMMA/ATH with wood, potentially leading to improved properties of so-called wood-plastic composites, or the acquisition of a new composite system that combines PMMA/ATH and wood. It has been found that the adhesives most commonly used in wood industry (ureaformaldehyde (UF), melamine urea-formaldehyde (MUF), and phenol-formaldehyde $(\mathrm{PF})$ ) can provide good bond strength between PMMA/ATH and wood [16]. In further work [13], PMMA/ATH powder was deposited on wood by cold plasma spraying using air as process and carrier gas. A functionalisation of the used PMMA/ATH material could be detected; however, it did not yield abrasion-resistant coatings. Therefore, the use as protective coatings on wood was not possible. In the present study, the replacement of air by forming gas was investigated, a factor which could yield more reactive molecule fragments and consequently improve the adhesion.

Moreover, our preliminary research suggested that PMMA/ATH boards and waste material are compatible with phenol-formaldehyde resin (PF) [16], yielding the opportunity to use this resin in the production of a recycled composite. PF are most often used in wood composite adhesives [21]. Powdered novolac PF can easily be combined with the PMMA/ATH powder for application by atmospheric cold plasma spraying. The use of a powdered phenol novolac resin with a medium hexamethylenetetramine (HMTA) content and medium flow turned out to be appropriate for the intended application. This kind of resin was intentionally formulated as a binding agent for the manufacturing of hot or highly compressed cold-pressed grinding wheels, where high thermal resistance and toughness are required. The resin used in this study melts at about $90^{\circ} \mathrm{C}$ and reacts at $130^{\circ} \mathrm{C}$. When cured, it has high dry and wet strength and is very resistant to water and damp atmospheres [21].

In previous studies on the abrasion resistance of PMMA/ ATH-based coatings [20], the replacement of air as process and carrier gas did not yield any improvement regarding particle fixation. The addition of PF to the PMMA/ATH base material, however, successfully stabilised the coatings. Therefore, this method provides a promising approach to recycling an industrial waste in consideration of the material's protective potential. Based on these previous results, the present research investigated morphologic and chemical properties as well as wettability of the resulting coatings to elucidate possible mechanisms that explain the outstanding adhesion achievable by the addition of PF and the failure of stabilisation by using forming gas. Moreover, adhesion tests were carried out to complement the previous studies on abrasion resistance.

\section{Materials and Methods}

2.1. Cold Plasma Spraying. The coatings were created by use of a setup as described previously [13, 20, 22, 23]. In short, the powder material was injected into the effluent plasma of a jet discharge generated by the application of a pulsed high voltage (ignition voltage: approx. $15 \mathrm{kV}$, effective voltage: $2-3 \mathrm{kV}$, max. input power: $2 \mathrm{~kW}$, pulse duration: 5-10 $\mu \mathrm{s}$, and pulse repetition rate: $50 \mathrm{kHz}$ ). The particle aerosol was obtained by homogeneously compressing dry powder in a cylindrical container and moving it against a rotating brush at a constant velocity defining the feed rate. The carrier gas was streamed above the brush to take up the powder and ensure its transport to the plasma source. To enable a coating of the entire surface, the samples were mounted on an $x y$-linear stage below the spraying nozzle. As in [20], two different modifications of this basic deposition process were investigated:

(A) use of pure PMMA/ATH powder with compressed air as process and carrier gas;

(B) use of forming gas instead of compressed air as process and carrier gas;

(C) addition of $10 \%$ phenol-formaldehyde powder (PF, Borofen BL-35 from Fenolit d. d.) to the PMMA/ATH powder with compressed air as process and carrier gas.

Coatings were generated on beech wood (Fagus sylvatica L., $4 \times 76 \times 26 \mathrm{~mm}^{3}$ ) and soda-lime glass (microscope slides) as a model substrate for surfaces that cannot be coated easily. Hereafter, wood and glass substrates are indicated with the coatings $\mathrm{A}, \mathrm{B}$, and $\mathrm{C}$, using indices $\mathrm{w}$ and $\mathrm{g}$, respectively. Applied deposition parameters are listed in Table 1. These parameters had to be adjusted separately for each coating material and process gas to avoid thermal damage to the wood samples and to concurrently ensure a homogeneous deposition.

2.2. Adhesion Tests. To investigate the adhesion of the different coatings, modified cross-cut tests were performed (based on DIN ISO 2409 [24]). For this purpose, a lattice of six cuts vertically and horizontally was prepared with a distance of $2 \mathrm{~mm}$ between parallel cuts. After carefully removing loose particles with compressed air, adhesive tape was applied and removed manually. For coated wood and glass, two replicates were prepared for each type of coating.

2.3. Layer Characterisation. Morphologic properties were studied by scanning electron microscopy (SEM) using a JSM$5600 \mathrm{LV}$ from Jeol USA Inc. at an accelerating voltage of $12 \mathrm{kV}$.

Surface sensitive chemical analysis of coated wood was carried out by use of X-ray photoelectron spectroscopy (XPS, PHI 5000 Versa Probe II from ULVAC-PHI). At room temperature and with a base pressure of $5 \times 10^{-8} \mathrm{~Pa}$, a spot of $200 \mu \mathrm{m}$ in diameter was irradiated using a monochromatic $\mathrm{Al} \mathrm{K} \alpha$ source $\left(1486.8 \mathrm{eV}\right.$ with $0.45 \mathrm{eV}$ FWHM $\left.\mathrm{Ag} 3 \mathrm{~d}_{5 / 2}\right)$. The pass energy was set to $187.85 \mathrm{eV}$ and $23.5 \mathrm{eV}$ for survey and detail spectra, respectively. For each powder or type 
TABLE 1: Summary of coating parameters (subscript w stands for wood and g for glass) [20].

\begin{tabular}{|c|c|c|c|c|c|c|}
\hline $\begin{array}{l}\text { Sample } \\
\text { number }\end{array}$ & Deposited material & $\begin{array}{l}\text { Process/carrier gas } \\
\quad \text { (flow rate) }\end{array}$ & $\begin{array}{c}\text { Carrier gas } \\
\text { pressure in } \mathrm{MPa}\end{array}$ & $\begin{array}{l}\text { Working distance } \\
\text { in } \mathrm{mm}\end{array}$ & $\begin{array}{l}\text { Powder feed rate in } \\
\qquad \mathrm{cm}^{3} / \mathrm{h}\end{array}$ & $\begin{array}{c}\text { Substrate } \\
\text { displacement in } \\
\mathrm{mm} / \mathrm{s}\end{array}$ \\
\hline $\mathrm{A}_{\mathrm{w} / \mathrm{g}}$ & PMMA/ATH & $\begin{array}{l}\text { Compressed air } \\
(40 \mathrm{~L} / \mathrm{min})\end{array}$ & 0.15 & 13 & 72 & 20 \\
\hline $\mathrm{B}_{\mathrm{w} / \mathrm{g}}$ & PMMA/ATH & $\begin{array}{l}\text { Forming gas } \\
(35 \mathrm{~L} / \mathrm{min})\end{array}$ & 0.1 & 25 & 121 & 100 \\
\hline $\mathrm{C}_{\mathrm{w} / \mathrm{g}}$ & $\begin{array}{c}\text { PMMA/ATH (90\%) } \\
\text { PF (10\%) }\end{array}$ & $\begin{array}{l}\text { Compressed air } \\
(40 \mathrm{~L} / \mathrm{min})\end{array}$ & 0.16 & 16 & 121 & 20 \\
\hline
\end{tabular}

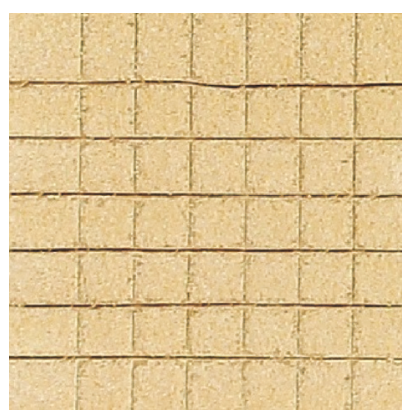

(a)

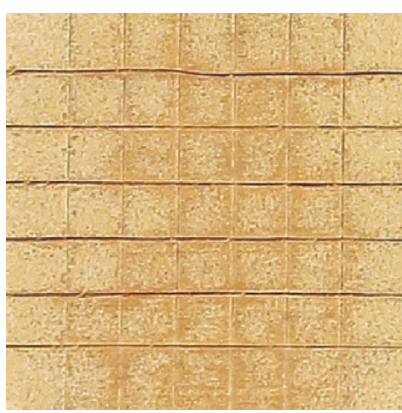

(b)

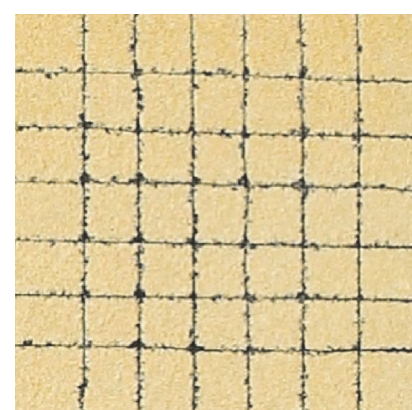

(c)

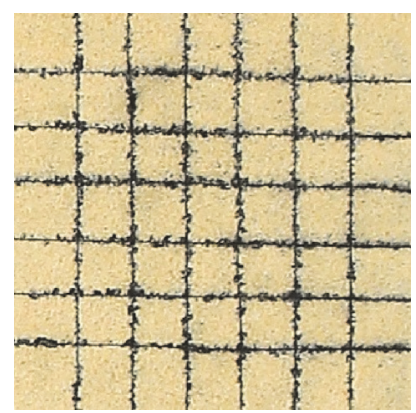

(d)

Figure 1: Cross-cut tests on wood and glass coated with PMMA/ATH and PF. (a): coated wood after first removal, (b) coated wood after 22nd removal, (c) coated glass after first removal, and (d) coated glass after 10th removal.

of coating, three survey and detail spectra were acquired. Charging of the nonconductive samples was minimised by applying the system's neutralisation system. Data processing was performed using the software MultiPak from PHI [25]. Binding energies are given with respect to the Fermi level and shifted to give an energy of $284.8 \mathrm{eV}$ for the main Cls subpeak (corresponding mainly to contributions from C-H, C-C, and $\mathrm{C}=\mathrm{C}$ ). For quantitative analysis and spectral deconvolution, the background (Shirley-type) was subtracted and symmetric Gauss-Lorentz profiles were fitted to the peaks. To account for both measurement and fitting errors, a total error of 5\% was assumed for all stoichiometric results.

In addition to XPS measurements, Fourier Transform Infrared Analysis (FTIR) was performed using a Frontier from PerkinElmer Inc. to study the functional groups involved in the powders and coatings. For this purpose, the coatings were removed from the glass substrates and mixed with $\mathrm{KBr}$ to form a pressed pellet. Spectra were acquired at a resolution of $4 \mathrm{~cm}^{-1}$ in the range of $4000-400 \mathrm{~cm}^{-1}$, each measurement representing the average of 32 spectra. For each system, three different tablets were prepared and analysed.

The wettability of the different coatings on wood was investigated by water contact angle measurements (measuring system G10 from Krüss GmbH). To do this, droplets of distilled water $(11 \mu \mathrm{L})$ were applied to the different surfaces and recorded for $10 \mathrm{~s}$ (25 frames/sec). Water contact angles were evaluated for each frame. On every coating, five measurements were carried out.

\section{Results and Discussion}

3.1. Adhesion. In addition to the abrasion tests carried out in previous studies [20], the adhesion was tested by applying and pulling off adhesive tape after cross-cutting the coating. On wood, PMMA/ATH coatings without the addition of PF powder were almost completely removed after the first withdrawal of tape (not shown). In contrast, samples $\mathrm{C}_{\mathrm{w} / \mathrm{g}}$ (addition of PF) showed only little change. However, coating material was attached to the adhesive tape. For the samples coated with PMMA/ATH and PF powder, the tests were therefore extended. It was found that most of the coating could be removed after multiple withdrawals of adhesive tape (see Figures 1(a) and 1(b)). Damage along the grid lines is assumed to result mainly from the cutting procedure. On wood, about 21 withdrawals still removed some coating material. The exact number is assumed to be strongly related to the layer thickness and should therefore only be taken as a rough relative estimate. For further withdrawals, no particles remained on the tape even though part of the coating was still present on the sample. Hence, the adhesion between the individual particles still needs improvement, but the bonding between the coating and the beech substrate already proved to be strong. The good adhesion to the substrate may be explained by secondary interactions between the wood constituents and the resin's hydroxyl groups [26]. These results support the hypothesis that complete removal of the coating on wood during the abrasion tests [20] was at least 


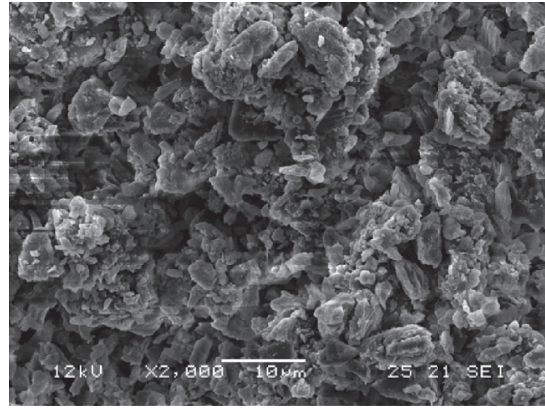

(a)

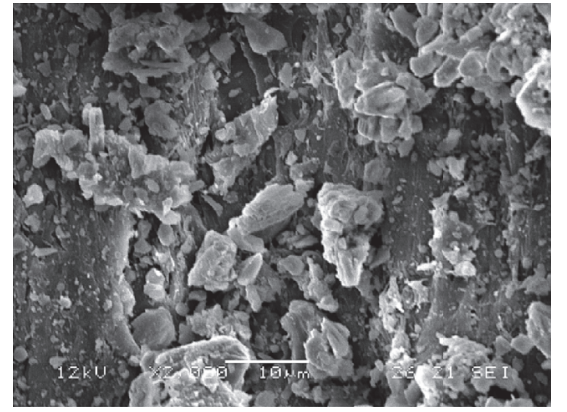

(b)

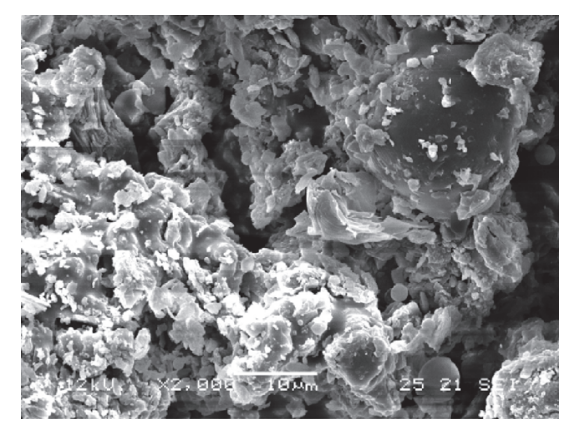

(c)

Figure 2: SEM images of different PMMA/ATH coatings on wood. (a): pure PMMA/ATH with air as process/carrier gas, (b): PMMA/ATH and forming gas as process/carrier gas, and (c): PMMA/ATH and PF powder coating with air as process/carrier gas.

TABLE 2: Elemental composition of the different samples as determined by XPS together with the resulting ratio O/C. Mean values of three measurements are displayed together with standard deviations in parentheses. Contributions from Na contamination are not listed.

\begin{tabular}{|c|c|c|c|c|c|}
\hline Sample & $\begin{array}{c}\text { O1s } \\
c \text { in at.\% }\end{array}$ & $\begin{array}{c}\mathrm{C} 1 \mathrm{~s} \\
c \text { in at.\% }\end{array}$ & $\begin{array}{c}\mathrm{Al} 2 \mathrm{p} \\
c \text { in at.\% }\end{array}$ & $\begin{array}{c}\text { N1s } \\
c \text { in at.\% }\end{array}$ & $\mathrm{O} / \mathrm{C}$ \\
\hline Untreated PMMA/ATH & $\begin{array}{l}49.8 \\
(0.8)\end{array}$ & $\begin{array}{l}38.4 \\
(0.5)\end{array}$ & $\begin{array}{c}11.8 \\
(0.4)\end{array}$ & & 1.3 \\
\hline $\begin{array}{l}\text { Coating } A_{w} \\
\text { (PMMA/ATH in air) }\end{array}$ & $\begin{array}{l}50.9 \\
(0.2)\end{array}$ & $\begin{array}{l}32.1 \\
(0.4)\end{array}$ & $\begin{array}{l}15.6 \\
(0.3)\end{array}$ & & 1.6 \\
\hline $\begin{array}{l}\text { Coating } \mathrm{B}_{\mathrm{w}} \\
\left(\text { PMMA/ATH in } \mathrm{N}_{2}+\mathrm{H}_{2}\right)\end{array}$ & $\begin{array}{c}47.8 \\
(0.8)\end{array}$ & $\begin{array}{l}37.5 \\
(1.2)\end{array}$ & $\begin{array}{l}13.7 \\
(0.4)\end{array}$ & & 1.3 \\
\hline Untreated PF & $\begin{array}{c}16.1 \\
(0.3)\end{array}$ & $\begin{array}{l}81.8 \\
(0.1)\end{array}$ & & $\begin{array}{c}2.2 \\
(0.2)\end{array}$ & 0.2 \\
\hline Untreated PF + PMMA/ATH & $\begin{array}{l}42.8 \\
(1.4)\end{array}$ & $\begin{array}{l}46.8 \\
(1.8)\end{array}$ & $\begin{array}{c}9.9 \\
(0.6)\end{array}$ & $\begin{array}{c}0.4 \\
(0.3)\end{array}$ & 0.9 \\
\hline $\begin{array}{l}\text { Coating } \mathrm{C}_{\mathrm{w}} \\
(\mathrm{PF}+\mathrm{PMM} / \mathrm{ATH} \text { in air })\end{array}$ & $\begin{array}{l}34.0 \\
(0.4)\end{array}$ & $\begin{array}{c}57.3 \\
(0.6)\end{array}$ & $\begin{array}{c}5.4 \\
(0.2)\end{array}$ & $\begin{array}{c}3.3 \\
(0.3)\end{array}$ & 0.6 \\
\hline
\end{tabular}

partly due to wood failure instead of insufficient adhesion between the coating and the substrate.

On glass (sample $\mathrm{C}_{\mathrm{g}}$ ), coating material was also still present on the adhesive tape after several removals ( 7 and 9 , resp.). For additional withdrawals, no coating material could be removed even though large parts were still on the sample. These results are in accordance with the abrasion tests [20], showing that the adhesion on glass was superior even to the adhesion on wood. Except for damage along the grid lines, the sample was still completely covered by the coating. In contrast, coatings without PF could be removed completely from glass substrates after only three withdrawals.

\subsection{Morphology. Figure 2 shows representative SEM images} of the different coatings (frame size: $48 \times 64 \mu \mathrm{m}^{2}$ ). Figures 2(a) and 2(b) display the pure PMMA/ATH coatings with air and forming gas as process and carrier gas, respectively. The shape and size of the individual particles did not differ from the untreated powder (not shown). No evidence is visible for film forming processes, therefore explaining the insufficient abrasion resistance and adhesion. In contrast, the coating based on a mixture of PMMA/ATH and PF powder (Figure 2(c)) appeared to feature no individual particles but rather particles that seemed to be fused. Presumably, the
PF covered the PMMA/ATH particles and, by melting or reacting in the plasma, it connected the particles and thus led to an improved abrasion resistance and adhesion. This hypothesis was also supported by XPS measurements (see below). However, the SEM measurements also revealed a very rough structure involving large spatial distances between the agglomerates. This large spatial distance together with the ragged shape of the particles may prevent sufficient contact of the individual agglomerates and could therefore explain the insufficient adhesion and abrasion resistance within the coatings.

3.3. Chemical Properties. XPS survey spectra showed a slight contamination from sodium for some coatings. Since its content did not exceed 1.5 at.\%, the Na contribution was taken into account when determining the chemical composition, but is not listed in this article. The elemental composition of the different systems is summarised in Table 2.

The composition of the untreated PMMA/ATH powder differed from previous results reporting an $\mathrm{Al}$ content of 7.2 at.\% [13], presumably because the powders originated from different production lots. When PMMA/ATH powder was deposited using air as carrier and process gas (sample $\mathrm{A}_{\mathrm{w}}$ ), the carbon content decreased while aluminium increased. 
Therefore, it is reasonable to assume PMMA was etched and thus ATH filler particles were uncovered. Accordingly, the ratio $\mathrm{O} / \mathrm{C}$ increased. Etching was also observed in [13], but to a higher extent (increase of $\mathrm{Al}$ content by a factor of about 2.2), supporting the fact that the deposition parameters (i.e., different process gas flow and particle feed rate in this case) influence the reactions in the plasma. Kuzuya et al. [27] proposed a chain scission mechanism to explain plasmaetching of PMMA. With forming gas as process and carrier gas (sample $\mathrm{B}_{\mathrm{w}}$ ), the increase in aluminium content was less pronounced. However, since the coating parameters had to be varied to avoid thermal damage to the substrates, direct comparison remains speculative.

With the addition of PF powder (10\%) to the PMMA/ ATH powder, a strong decrease of aluminium content together with a significant increase in carbon and nitrogen took place. Aluminium indicates the presence of PMMA/ATH, whereas nitrogen occurs in the HMTA contained in the PF powder. Therefore, these results suggest that, after deposition, the reacted PF encased the PMMA/ATH particles, which could explain both the fusion of the particles observed with SEM and the enhanced adhesion. Moreover, the nitrogen content of the deposited coatings (sample $\mathrm{C}_{\mathrm{w}}$ ) exceeded even those of pure PF powder. This may be explained by the incorporation of nitrogen from the ionised atmosphere during the deposition process [28]. A thorough characterisation of this specific plasma setup is still subject to current and future projects, but preliminary measurements showed a predomination of $\mathrm{NO}$ and $\mathrm{OH}$ species in the plasma, thus supporting the hypothesis of nitrogen incorporation. In addition, the plasma is likely to open the phenolic rings to some extent, thus forming chains of conjugated double bonds. Such reactions are well known to be the result of direct and remote plasma treatments in oxygen containing atmospheres for a variety of polymers containing phenol groups, such as polystyrene, bisphenol A polycarbonate, polyethylene terephthalate, or polyphenylsulfone [29-31]. Due to steric effects, this modified structure might acquire a higher density and, therefore, the HMTA could be overrepresented on the surface.

To further study the changes induced by the plasma treatments, the C1s peak was decomposed into its different contributions. The different untreated materials already feature a complex carbonic structure, leading to various overlapping peaks, and the different plasma treatments induced further major changes. Therefore, not every individual bond could be isolated in a reliable way. Instead, peaks covering different regions were fitted to the C1s. According to the literature [3238], these regions were defined as follows:

(i) C1: Contributions from $\mathrm{C}-\mathrm{H}$, but also $\mathrm{C}-\mathrm{C}$ and $\mathrm{C}=\mathrm{C}$ bonds (overlap with $\mathrm{C} 2$ ), shifted to $E_{\mathrm{C} 1}=284.8 \mathrm{eV}$;

(ii) $\mathrm{C} 2$ : located at a binding energy of $E_{\mathrm{Cl}}+(1.3$ to 1.7$) \mathrm{eV}$, mainly accounting for $\mathrm{C}-\mathrm{O}, \mathrm{C}-\mathrm{OH}, \mathrm{CN}$, and $\mathrm{C}-\mathrm{O}-\mathrm{C}$, but with contributions from $\mathrm{C}-\mathrm{C}$ and $\mathrm{C}=\mathrm{C}$ bonds;

(iii) C3: at $E_{\mathrm{C} 1}+(2.8$ to 3.3$) \mathrm{eV}$, representing $\mathrm{C}=\mathrm{O}$ and $\mathrm{O}$ $\mathrm{C}-\mathrm{O}$;

(iv) $\mathrm{C} 4$ : at $E_{\mathrm{Cl}}+(3.8$ to 4.0$) \mathrm{eV}$, corresponding to $\mathrm{O}-\mathrm{C}=\mathrm{O}$.
Moreover, the full width at half maximum (FWHM) was constrained to be the same for all peaks within each deconvolution. Even though this assumption is expected to cause distortion of the results to some extent, the constraint was needed for a thorough fitting procedure, taking into account the variety of carbon bonds that may occur. The quantitative results should thus only be taken as an estimate.

The C1s peaks along with the decomposition for the systems are displayed in Figure 3 for representative spectra and quantitative results are summarised in Table 3. For all samples except the untreated PMMA/ATH powder, mean values of three measurements are listed. One measurement of untreated PMMA/ATH powder led to very different results than the other two and literature values [32]; therefore the third measurement was excluded and the values represent the mean of only two measurements. The distortion may be explained by contamination which was likely to occur because the powder represents an industrial waste.

In accordance with previous results [13], the deposition of PMMA/ATH powder with the use of air as process and carrier gas (coating $A_{w}$ ) led to a slight oxidation of the PMMA, indicated by a decrease of $\mathrm{C} 1$ for the benefit of $\mathrm{C} 3$ and C4. In contrast, the use of forming gas instead of air as process and carrier gas seemed to cause a more severe fragmentation and recombination, presumably involving high loss of hydrogen side-chains $\left(\mathrm{CH}_{2}, \mathrm{CH}_{3}\right)$ as supported by the decreasing $\mathrm{C} 1$ peak. The increase in $\mathrm{C} 2$ may partly be caused by fragmentation and subsequent formation of $\mathrm{C}-\mathrm{OH}$ or C-O-C groups. The shake-up around $292.6 \mathrm{eV}$ indicates the generation of $\mathrm{C}=\mathrm{C}$ or other unsaturated bonds. Even though the elemental composition indicated a slight reduction of the PMMA, the oxidative compounds within the $\mathrm{Cls}$ peak seemed to increase. This is assumed to result from an overlap of the regions, particularly C1 and C2 which cover various different compounds. Presumably, a strong loss of hydrogen-containing side-chains along with an increase in $\mathrm{C}-\mathrm{C}$ (relative) and $\mathrm{C}=\mathrm{C}$ bonds distorted the results since the $\mathrm{C}-\mathrm{H}$ and $\mathrm{C}-\mathrm{C} / \mathrm{C}=\mathrm{C}$ bonds were summarised as one region despite the difference in binding energy of about $0.72 \mathrm{eV}$ [32]. Nevertheless, the formation of new $\mathrm{C}=\mathrm{O}$ bonds was strongly supported by the data and evidence for severe fragmentation was found. These results may be explained by depolymerisation of PMMA in the plasma through chain scission and depletion of methyl/methylene groups.

The deposition of PMMA/ATH and PF powder with air as process/carrier gas seemed to cause oxidation. Since the results from the elemental composition on the surface and SEM measurements indicated a predominant concentration of PF rather than PMMA on the surface, the oxidation is assumed to affect mainly the resin instead of PMMA during deposition. However, complementary analysis would be needed to elucidate the processes involved.

Since the information depth of XPS usually is well below $10 \mathrm{~nm}$, these measurements cannot be used to study the adhesion mechanism between the coating and the substrates directly. However, the results did suggest that PF underwent distinct chemical changes during the plasma treatment. On wood, the PF's hydroxyl groups are assumed to interact with the wood constituents and ensure bonding [26]. On the 


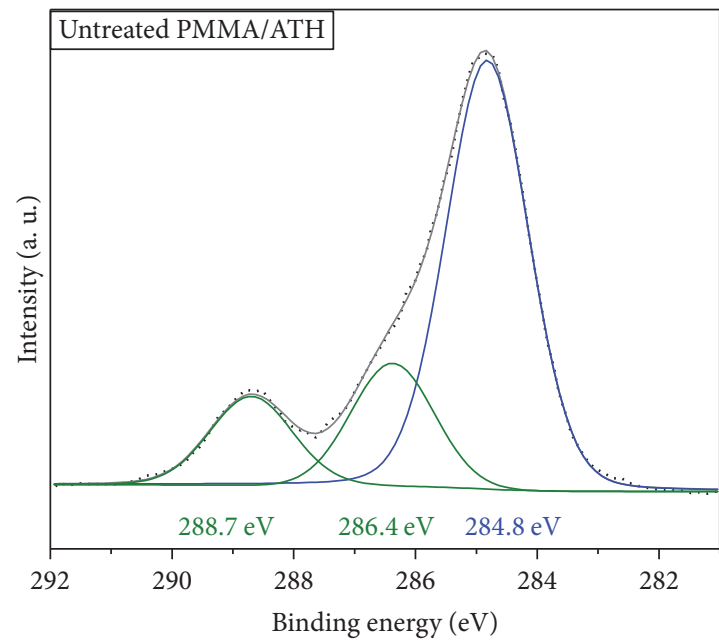

(a)

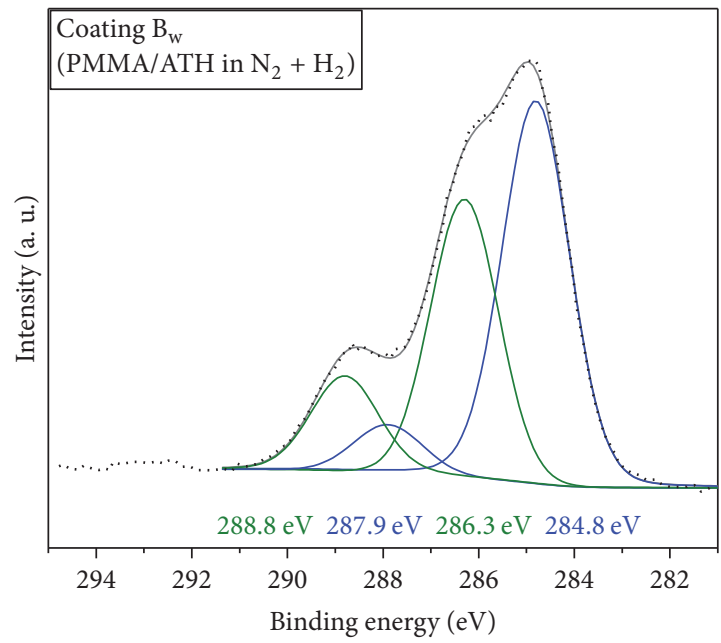

(c)

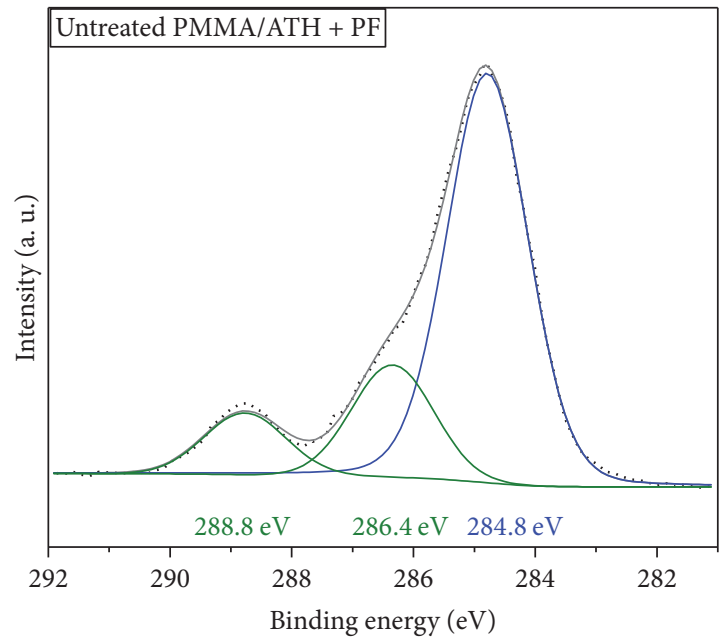

(e)

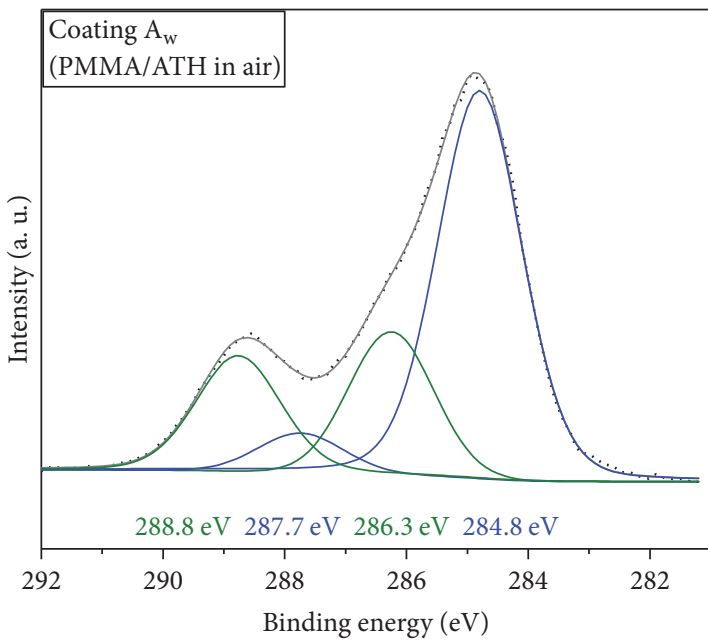

(b)

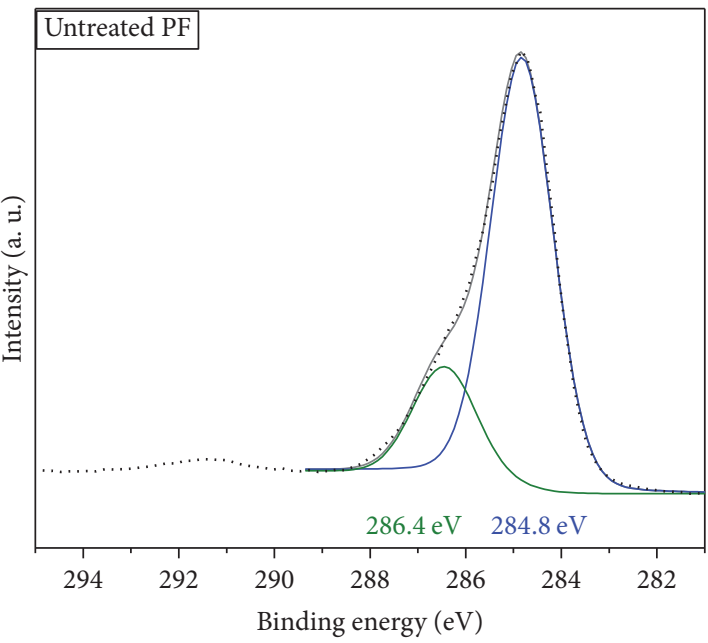

(d)

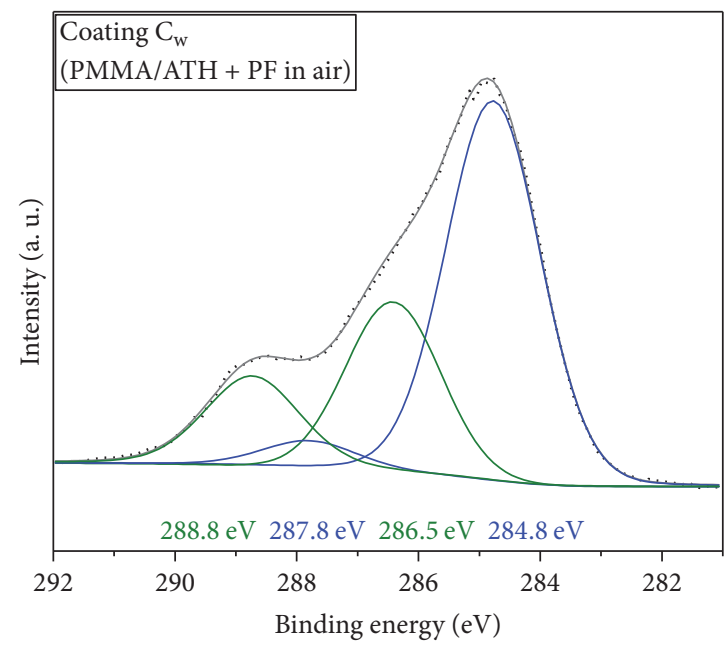

(f)

FIGURE 3: Representative deconvolutions of the Cls peaks. Solid grey line: cumulative fit; dotted line: measured data. The binding energies of the subpeaks corresponding to regions $\mathrm{Cl}-\mathrm{C} 4$ are depicted below the spectra. Region $\mathrm{Cl}$ : C-H, C-C, C=C; region C2: C-O, C-OH, C-N, $\mathrm{C}-\mathrm{O}-\mathrm{C},(\mathrm{C}-\mathrm{C}, \mathrm{C}=\mathrm{C})$; region $\mathrm{C} 3$ : $\mathrm{C}=\mathrm{O}$, O-C-O; region $\mathrm{C} 4$ : $\mathrm{O}-\mathrm{C}=\mathrm{O}$. 
TABLE 3: Spectral deconvolution of the C1s peaks. $A_{\text {meas }}$ denotes the measured relative area of the specific carbon bonds within the C1s. Values in parentheses denote standard deviations. ${ }^{*}$ One measurement of untreated PMMA/ATH powder was probably distorted by contamination; therefore, the values given in this case are mean values of only two measurements.

\begin{tabular}{|c|c|c|c|c|}
\hline Sample & $\begin{array}{c}\mathrm{Cl} \\
\mathrm{C}-\mathrm{H}, \mathrm{C}-\mathrm{C}, \mathrm{C}=\mathrm{C} \\
A_{\text {meas }} \text { in } \%\end{array}$ & $\begin{array}{c}\mathrm{C} 2 \\
\mathrm{C}-\mathrm{O}, \mathrm{C}-\mathrm{OH}, \mathrm{C}-\mathrm{N}, \\
\mathrm{C}-\mathrm{O}-\mathrm{C} \\
(\mathrm{C}-\mathrm{C}, \mathrm{C}=\mathrm{C}) \\
A_{\text {meas }} \text { in } \%\end{array}$ & $\begin{array}{c}\mathrm{C} 3 \\
\mathrm{C}=\mathrm{O}, \mathrm{O}-\mathrm{C}-\mathrm{O} \\
A_{\text {meas }} \text { in } \%\end{array}$ & $\begin{array}{c}\mathrm{C} 4 \\
\mathrm{O}-\mathrm{C}=\mathrm{O} \\
A_{\text {meas }} \text { in \% }\end{array}$ \\
\hline Untreated PMMA/ATH ${ }^{*}$ & $\begin{array}{l}67.5 \\
(0.1)\end{array}$ & $\begin{array}{l}18.6 \\
(0.1)\end{array}$ & $\begin{array}{c}0.0 \\
(0.0)\end{array}$ & $\begin{array}{l}13.9 \\
(0.0)\end{array}$ \\
\hline $\begin{array}{l}\text { Coating } \mathrm{A}_{\mathrm{w}} \\
\text { (PMMA/ATH in air) }\end{array}$ & $\begin{array}{l}60.5 \\
(2.4)\end{array}$ & $\begin{array}{l}18.9 \\
(0.7)\end{array}$ & $\begin{array}{c}4.0 \\
(1.4)\end{array}$ & $\begin{array}{l}16.6 \\
(0.7)\end{array}$ \\
\hline $\begin{array}{l}\text { Coating } \mathrm{B}_{\mathrm{w}} \\
\text { (PMMA/ATH in } \mathrm{N}_{2}+\mathrm{H}_{2} \text { ) }\end{array}$ & $\begin{array}{l}48.7 \\
(1.2)\end{array}$ & $\begin{array}{l}32.3 \\
(1.3)\end{array}$ & $\begin{array}{c}6.5 \\
(0.7)\end{array}$ & $\begin{array}{l}12.5 \\
(0.5)\end{array}$ \\
\hline Untreated PF & $\begin{array}{l}80.9 \\
(0.2)\end{array}$ & $\begin{array}{c}19.1 \\
(0.2)\end{array}$ & $\begin{array}{c}0.0 \\
(0.0)\end{array}$ & $\begin{array}{c}0.0 \\
(0.0)\end{array}$ \\
\hline Untreated PF + PMMA/ATH & $\begin{array}{l}69.9 \\
(1.3)\end{array}$ & $\begin{array}{l}19.3 \\
(0.7)\end{array}$ & $\begin{array}{c}0.0 \\
(0.0)\end{array}$ & $\begin{array}{l}10.8 \\
(0.6)\end{array}$ \\
\hline $\begin{array}{l}\text { Coating } \mathrm{C}_{\mathrm{w}} \\
(\mathrm{PF}+\mathrm{PMMA} / \mathrm{ATH} \text { in air })\end{array}$ & $\begin{array}{l}58.6 \\
(1.6) \\
\end{array}$ & $\begin{array}{l}24.1 \\
(0.7) \\
\end{array}$ & $\begin{array}{c}3.6 \\
(1.5) \\
\end{array}$ & $\begin{array}{l}13.7 \\
(2.0)\end{array}$ \\
\hline
\end{tabular}

surface of $\mathrm{SiO}_{2}$, hydroxyl groups usually play an important role as well [39]. Since plasma treatments involving oxygen species are known to activate surfaces $[38,40]$, the $\mathrm{C}-\mathrm{OH}$ groups of the PF could react with the $\mathrm{Si}-\mathrm{OH}$ bond of the glass surface in the presence of an activating plasma, leading to the release of $\mathrm{H}_{2} \mathrm{O}$ and the formation of covalent C-O-Si bonds on the interface. Since, even in nonpure $\mathrm{SiO}_{2}$ glass, the density of such functional groups is assumed to be higher on $\mathrm{SiO}_{2}$ than on wood, this could explain the outstanding adhesion on glass compared to wood.

In addition to XPS measurements, infrared spectra of the coatings were acquired by scraping off the layer, mixing it with $\mathrm{KBr}$, and forming a pressed pellet. These transmittance spectra were recorded because the high surface roughness which prevented close contact with the ATR crystal made ATR-FTIR measurements impossible. Figure 4 shows representative spectra of untreated PMMA/ATH powder, the untreated mixture of PMMA/ATH and PF powder, and the deposited coating $\mathrm{C}_{\mathrm{g}}$. In the spectrum of PMMA/ATH powder, the hydroxyl groups from ATH mainly manifest in the region between 3700 and $3200 \mathrm{~cm}^{-1}$, around $1021 \mathrm{~cm}^{-1}$, and between approximately 900 and $459 \mathrm{~cm}^{-1}$ [41]. Moreover, PMMA predominantly appears around $2998 \mathrm{~cm}^{-1}$, $2952 \mathrm{~cm}^{-1}, 1487 \mathrm{~cm}^{-1}, 1452 \mathrm{~cm}^{-1}, 1390 \mathrm{~cm}^{-1}\left(\mathrm{CH}_{2}, \mathrm{CH}_{3}\right)$, and $1732 \mathrm{~cm}^{-1}(\mathrm{C}=\mathrm{O})$ [42]. The addition of PF powder led to the appearance of new peaks which were much more pronounced for the deposited coating. For the coating, the hydroxyl region between 3700 and $3200 \mathrm{~cm}^{-1}$ was strongly broadened towards lower wavenumbers, resulting from the PF's $\mathrm{C}-\mathrm{OH}$ bonds. Moreover, phenolic $\mathrm{C}=\mathrm{C}$ manifested at $1612 \mathrm{~cm}^{-1}$, $1595 \mathrm{~cm}^{-1}$, and $1513 \mathrm{~cm}^{-1}$. The band around $1240 \mathrm{~cm}^{-1}$ may be assigned to $\mathrm{C}-\mathrm{O}$ or $\mathrm{C}-\mathrm{OH}[43,44]$. Since the FTIR spectra include information from the coating's bulk material, they confirm a strong dominance by PF not only on the surface. This dominance may result from both an encasement of the

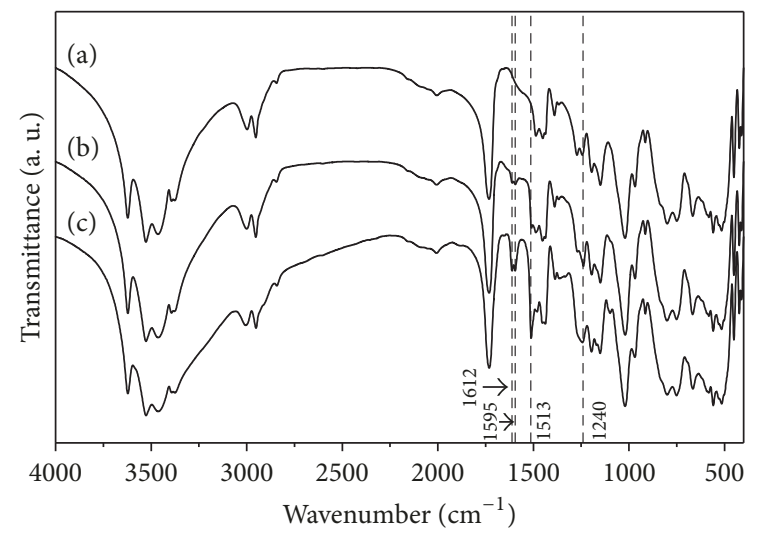

FIGURE 4: IR-spectra of untreated PMMA/ATH powder (a), untreated mixed PMMA/ATH and PF powder (b), and coating $\mathrm{C}_{\mathrm{g}}$ (c).

PMMA/ATH particles and an etching of PMMA during the deposition.

Infrared spectra were also recorded for the other coatings. However, since all chemical moieties changed during the deposition, normalisation was found to be challenging. No reliable additional information could be extracted from those spectra; therefore, they are not presented in this article.

3.4. Wettability. Figure 5 shows the evolution of the water contact angles on the different samples. For each time interval, the mean of five measurements is given. In accordance with [13], the contact angles on coating $A_{w}$ (Figure 5(a)) decreased quickly and the droplet was absorbed within $10 \mathrm{~s}$. This behaviour is assumed to result from a combination of the rough surface as well as from the chemical changes, namely, the exposure of ATH and thus of hydroxyl groups and 


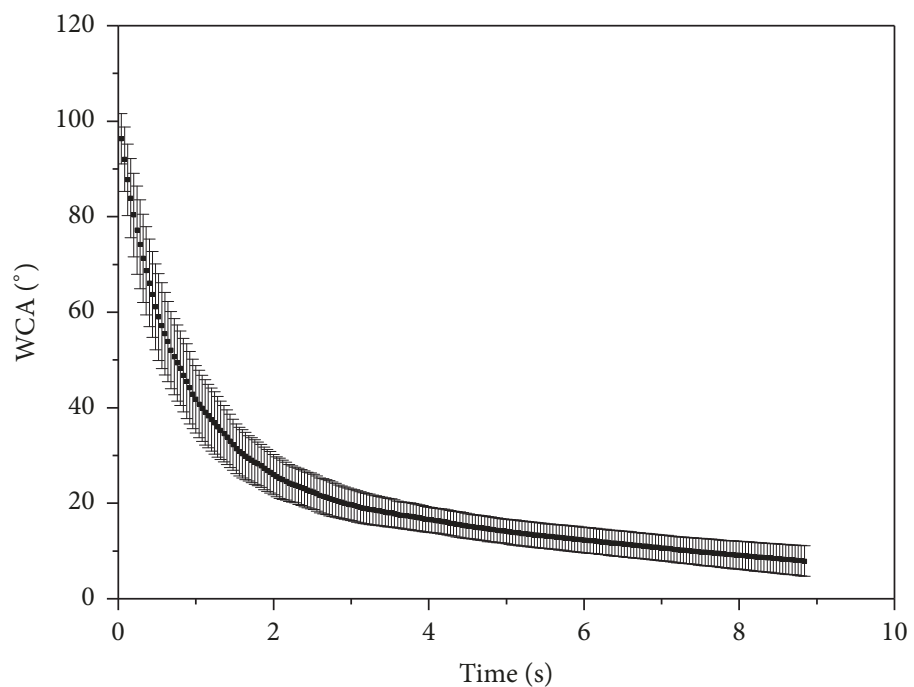

(a)

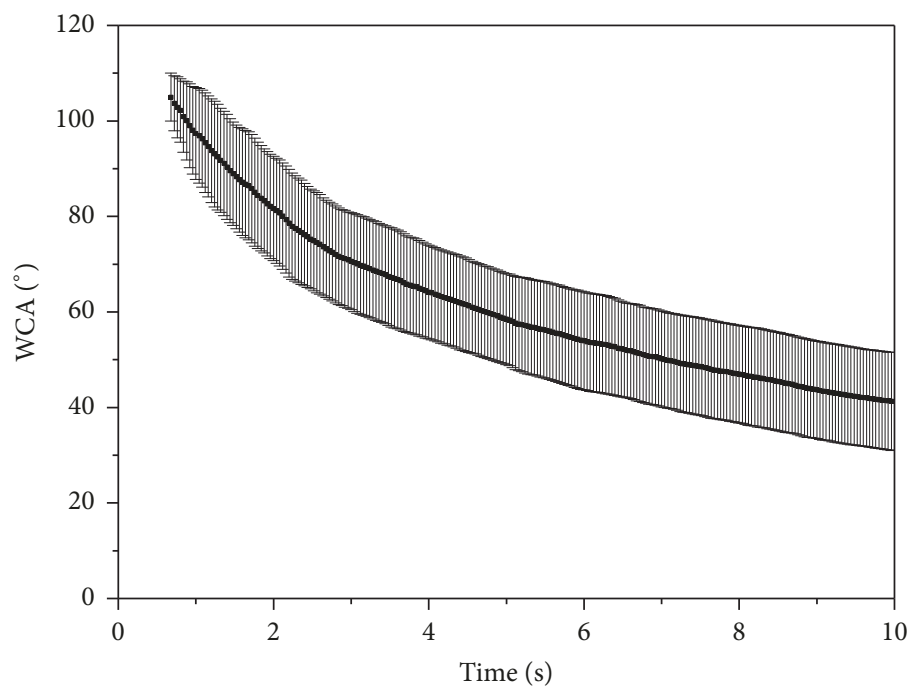

(b)

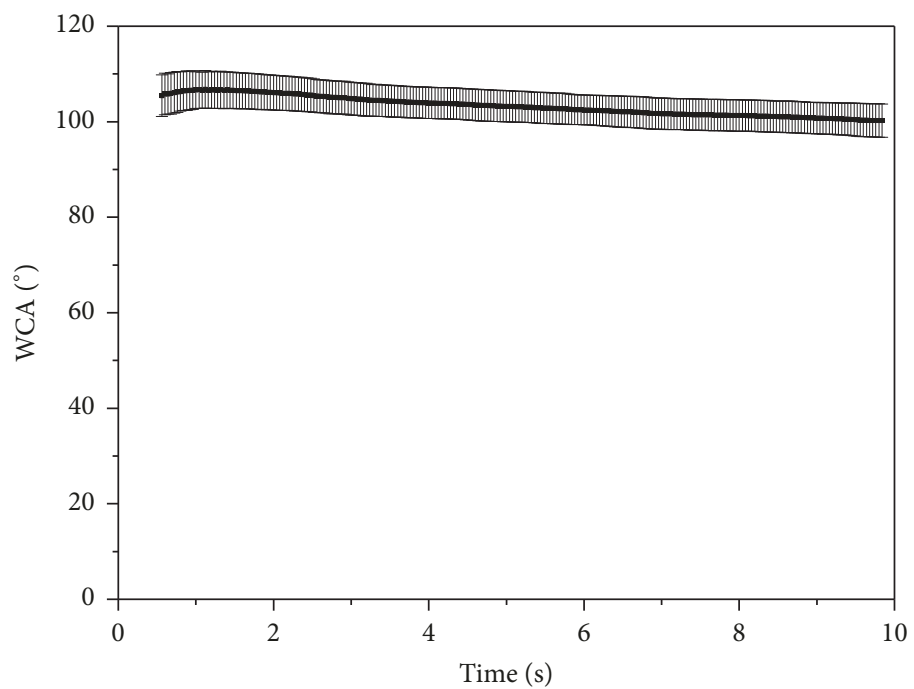

(c)

FIgURE 5: Evolution of the water contact angle with time. (a): coating $A_{w}$, (b): coating $B_{w}$, and (c): coating $C_{w}$. 
the oxidation of PMMA. Sample $\mathrm{B}_{\mathrm{w}}$ (Figure 5(b)) appeared to be slightly less hydrophilic, presumably because of less intense etching of PMMA and therefore less ATH on the surface. Moreover, it supports the hypothesis that nonpolar $\mathrm{C}-\mathrm{C}$ and $\mathrm{C}=\mathrm{C}$ bonds dominate and that the apparent increase in polar groups observed for XPS measurements (peak C2) was merely an inaccuracy resulting from the strong overlap of the peaks. In contrast, sample $\mathrm{C}_{\mathrm{w}}$ (Figure 5(c)) was found to be hydrophobic (contact angles above $100^{\circ}$ ), which should result from the significantly increased carbon content on the surface and the decreased share of ATH. Therefore, an application of optimised coatings based on PMMA/ATH and $\mathrm{PF}$ powder as protective, hydrophobic coatings is conceivable.

\section{Conclusion and Outlook}

In this work, cold plasma spraying was used to deposit different kinds of coatings based on PMMA/ATH waste powder to explore possible recycling options as protective layers. The adhesion of the resulting coatings was investigated together with their morphologic and chemical properties to study possible adhesion mechanisms and changes during the plasma treatments.

In an attempt to increase the adhesion of PMMA/ATH coatings to wood and glass substrates, the process and carrier gas was replaced by forming gas. Even though chemical analysis confirmed severe fragmentation and recombination of carbonic compounds, no improvement of the adhesion could be obtained. As for PMMA/ATH coatings deposited with air as process and carrier gas, SEM measurements did not show any evidence for film forming mechanisms.

In contrast, the addition of a novolac phenol-formaldehyde resin with medium HMTA content significantly enhanced the coating's adhesion, particularly between the coating and the substrate. SEM measurements revealed a fusion of individual particles, but also a very rough surface leading to large spatial distances between larger agglomerations of particles. Therefore, the enhanced but not yet sufficient adhesion between the particles/agglomerates within the coating is assumed to result from a morphologic rather than from a chemical problem. In accordance with the observed fusion of particles on the surface, chemical analysis by XPS and FTIR provided strong evidence for the formation of an envelope around the PMMA/ATH particles made of PF that has reacted in the plasma. In the infrared spectra, a strong increase of PF-related bands was observed, even though only $10 \%$ resin was added to the PMMA/ATH base material. Moreover, XPS measurements revealed an increase of carbon and nitrogen content, supporting a predomination of PF on the surface. Changes in the carbonic structure are therefore assumed to occur mainly in PF. Even though the interface between the coating and the surfaces could not be studied, the reactivity of PF in the plasma supports the hypothesis of interactions between the $\mathrm{C}-\mathrm{OH}$ groups of $\mathrm{PF}$ and $\mathrm{Si}-\mathrm{OH}$ on the glass surface yielding $\mathrm{C}-\mathrm{O}-\mathrm{Si}$ bonds and releasing water following the plasma treatment. The high density of functional groups on glass surfaces may explain the outstanding adhesion between the coating and the substrate. In addition, water contact angle measurements showed hydrophobic properties of the coatings with angles above $100^{\circ}$, therefore generally permitting an application of such coatings, for example, to reduce water uptake by wood.

The results suggest that highly adhesive and abrasionresistant coatings on wood and glass substrates can be achieved by further optimising such coatings generated by cold plasma spraying with mixed PMMA/ATH and PF powder. Since the problems with adhesion within the coatings are assumed to arise from the morphologic and not from the chemical nature, further studies could concentrate on variations of the deposition parameters to reduce piling of particles and agglomerates. For example, the substrate displacement velocity might distinctly impact the resulting structural properties. Moreover, a grinding of PMMA/ATH particles prior to the deposition could contribute to smoother surfaces. Following optimisation, the coatings' protective potential could be explored. Hydrophobic properties were already shown in this work, but the base material features other outstanding properties favourable to the protection of wood or other materials (cf. Introduction). Therefore, it could be assessed whether some of these potentially protective properties were transferred to the coatings.

\section{Conflicts of Interest}

The authors declare that there are no conflicts of interest regarding the publication of this paper.

\section{Acknowledgments}

The authors gratefully acknowledge financial support from the Lower Saxony Ministry of Science and Culture (MWK) as well as by the Open Access Publication Funds of the Göttingen University. The authors also thank Kolpa d. d. for providing the coating materials, Mirco Weber for fruitful discussions about the results, and Roger Skarsten for proofreading the manuscript.

\section{References}

[1] "Plastics - Decorative solid surfacing materials - Part 2: Determination of properties - Sheet goods," in ISO 19712-2, 2007.

[2] R. B. Duggins and C. Ford, US 3847865: Use of alumina trihydrate in a polymethyl methacrylate article, 1974.

[3] R. B. Duggins, C. Ford, H. C. Miller et al., US 3827933: Filled polymethyl methacrylate article and a process for its manufacture, 1974.

[4] P. Gilormini, L. Chevalier, and G. Régnier, "Modeling the nonlinear PMMA behavior near glass transition temperature: Application to its thermoforming," in Proceedings of the International Conference on Advances in Materials and Processing Technologies, AMPT2010, pp. 179-184, France, October 2010.

[5] E. M. Gunel and C. Basaran, "Micro-deformation mechanisms in thermoformed alumina trihydrate reinforced poly(methyl methacrylate)," Materials Science and Engineering: A Structural Materials: Properties, Microstructure and Processing, vol. 523, no. 1-2, pp. 160-172, 2009. 
[6] R. G. Jagger and A. Okdeh, "Thermoforming polymethyl methacrylate," The Journal of Prosthetic Dentistry, vol. 74, no. 5, pp. 542-545, 1995.

[7] E. Minghetti, US 6562927 B1: Method of making a thermoformable article having uniform distribution of coloring and mineral filler before and after thermoforming, 2003.

[8] S. Sabesan, US 8092815 B2: Antimicrobial solid surface materials containing chitosan-metal complexes, 2012.

[9] W. Kaminsky and J. Franck, "Monomer recovery by pyrolysis of poly(methyl methacrylate) (PMMA)," Journal of Analytical and Applied Pyrolysis, vol. 19, no. C, pp. 311-318, 1991.

[10] W. Kaminsky, M. Predel, and A. Sadiki, "Feedstock recycling of polymers by pyrolysis in a fluidised bed," Polymer Degradation and Stability, vol. 85, no. 3, pp. 1045-1050, 2004.

[11] J. Hochberg and R. B. Young, US 4759774 A: Process for cleaning substrates, 1988.

[12] E. Šušteršič, M. Tušar, and A. Zupančič Valant, "Rheological and mechanical characterization of waste PMMA/ATH modified bitumen," Construction and Building Materials, vol. 38, pp. 119$125,2013$.

[13] L. M. Wallenhorst, S. Dahle, M. Vovk et al., "Characterisation of PMMA/ATH layers realised by means of atmospheric pressure plasma powder deposition," Advances in Condensed Matter Physics, vol. 2015, Article ID 980482, 2015.

[14] M. Tušar, E. Šušteršič, and A. Zupančič-Valant, "Alternative PMB produced from recycling waste PMMA/ATH," Transport Problems, vol. 9, no. 2, pp. 5-9, 2014.

[15] M. Tuar, A. Belicic, M. Preeren, M. Tušar, A. Beličič, and M. Prešeren, EP 20130730823: Modified bitumen and its use for preparing asphalt mixtures and bituminous products, 2015.

[16] M. Vovk, M. ernek, and M. Šernek, "Lepljenje lesa in Kerrocka," Pedagoška obzorja 2, vol. 2015, no. 4, 2015.

[17] M. Vovk, A. Belicic, M. Sernek, and A. Beličič, "Združljivost lesa s kompozitom iz polimetilmetakrilata in aluminijevega hidroksida (Compatibility of wood with a composite from polymethyl methacrylate and aluminium hydroxide)," in Znanstveno srečanje Gozd in les, pp. 11-13, 2014.

[18] M. Vovk, L. Wallenhorst, C. Kaldun et al., "Air plasma treatment of aluminium trihydrate filled poly(methyl methacrylate)," Journal of Adhesion Science and Technology, pp. 1-23, 2017.

[19] M. Vovk, M. Šernek, A. Belicic, and M. Šernek, "Postopek za pridobivanje kompozitnega materiala iz odpadnih produktov PMMA/ATH kompozita, vezanih z aminoplastičnimi ali fenolnimi lepili," SI patent 24705 A, 10 pages, 2015.

[20] L. Wallenhorst, R. Rerich, and M. Vovk, "Enhancing the abrasion resistance of PMMA/ATH layers realised by means of atmospheric pressure plasma powder deposition on wood," in Proceedings of the in Proceedings of the 11th International Conference Wood Science and Engineering in the third Millenium, 2017.

[21] United states department of agriculture, Wood handbook: Wood as an engineering material, Forest product Laboratory, USDA, Madison, Wis, USA, 2010.

[22] P. Gascón-Garrido, N. Mainusch, H. Militz, W. Viöl, and C. Mai, "Copper and aluminium deposition by cold-plasma spray on wood surfaces: effects on natural weathering behaviour," European Journal of Wood and Wood Products, vol. 75, no. 3, pp. 315-324, 2017.

[23] P. Gascón-Garrido, N. Mainusch, H. Militz, W. Viöl, and C. Mai, "Effects of copper-plasma deposition on weathering properties of wood surfaces," Applied Surface Science, vol. 366, pp. 112-119, 2016.
[24] "Paints and varnishes - Cross-cut test," DIN EN ISO 2409, 2013.

[25] MultiPak, Physical Electronics Inc, Chanhassen, Minn, USA.

[26] M.-P. G. Laborie and C. E. Frazier, "13C CP/MAS NMR study of a wood/phenol-formaldehyde resin bondline," Journal of Materials Science, vol. 41, no. 18, pp. 6001-6005, 2006.

[27] M. Kuzuya, A. Noguchi, M. Ishikawa et al., "Electron spin resonance study of free-radical formation and its decay of plasma-irradiated poly(methacrylic acid) and its esters," The Journal of Physical Chemistry C, vol. 95, no. 6, pp. 2398-2403, 1991.

[28] H. Yasuda and T. Yasuda, "Competitive ablation and polymerization (CAP) principle and the plasma sensitivity of elements in plasma polymerization and treatment," Journal of Polymer Science Part A: Polymer Chemistry, vol. 38, no. 6, pp. 943-953, 2000.

[29] E. Gonzalez II, M. D. Barankin, P. C. Guschl, and R. F. Hicks, "Ring opening of aromatic polymers by remote atmosphericpressure plasma," IEEE Transactions on Plasma Sciences, vol. 37, no. 6, pp. 823-831, 2009.

[30] L. J. Gerenser, "XPS Studies Of In Situ Plasma-Modified Polymer Surfaces," Journal of Adhesion Science and Technology, vol. 7, no. 10, pp. 1019-1040, 1993.

[31] D. Zhang, S. M. Dougal, and M. S. Yeganeh, "Effects of UV irradiation and plasma treatment on a polystyrene surface studied by IR-visible sum frequency generation spectroscopy," Langmuir, vol. 16, no. 10, pp. 4528-4532, 2000.

[32] G. Beamson and D. Briggs, High resolution XPS of organic polymers, Wiley, 1992.

[33] T. Cai, M. Zhou, D. Ren, G. Han, and S. Guan, "Highly ordered mesoporous phenol-formaldehyde carbon as supercapacitor electrode material," Journal of Power Sources, vol. 231, pp. 197202, 2013.

[34] A. Crunteanu, M. Charbonnier, M. Romand et al., "Synthesis and characterization of carbon nitride thin films obtained by laser induced chemical vapour deposition," Surface and Coatings Technology, vol. 125, no. 1-3, pp. 301-307, 2000.

[35] C. Moreno-Castilla, M. V. López-Ramón, and F. CarrascoMarín, "Changes in surface chemistry of activated carbons by wet oxidation," Carbon, vol. 38, no. 14, pp. 1995-2001, 2000.

[36] B. P. Payne, M. C. Biesinger, and N. S. McIntyre, "X-ray photoelectron spectroscopy studies of reactions on chromium metal and chromium oxide surfaces," Journal of Electron Spectroscopy and Related Phenomena, vol. 184, no. 1-2, pp. 29-37, 2011.

[37] M. N. Uddin, O. A. Fouad, M. Yamazato, and M. Nagano, "Deposition and characterization of carbon nitride films from hexamethylenetetramine/N2 by microwave plasma-enhanced chemical vapor deposition," Applied Surface Science, vol. 240, no. 1-4, pp. 120-130, 2005.

[38] P. Král, J. Ráhel', M. Stupavská et al., "XPS depth profile of plasma-activated surface of beech wood (Fagus sylvatica) and its impact on polyvinyl acetate tensile shear bond strength," Wood and Science Technology, vol. 49, no. 2, pp. 319-330, 2014.

[39] P. Schönherr, Multiple Oberflächenfunktionalisierung von Mischgläser- und Siliciumdioxidpartikeln als Komponenten für [Dissertation, thesis], Technical University Chemnitz, 2013.

[40] E. Kondoh, T. Asano, A. Nakashima et al., "Effect of oxygen plasma exposure of porous spin-on-glass films," Journal of Vacuum Science Technology B: Microelectronics and Nanometer Structures Processing, Measurement, and Phenomena, vol. 18, no. 3, pp. 1276-1280, 2000. 
[41] J. T. Kloprogge, H. D. Ruan, and R. L. Frost, “Thermal decomposition of bauxite minerals: Infrared emission spectroscopy of gibbsite, boehmite and diaspore," Journal of Materials Science, vol. 37, no. 6, pp. 1121-1129, 2002.

[42] H. Nagai, "Infrared spectra of stereoregular polymethyl methacrylate," Journal of Applied Polymer Science, vol. 7, no. 5, pp. 1697-1714, 1963.

[43] R. O. Ebewele, B. H. River, and J. A. Koutsky, "Relationship between phenolic adhesive chemistry and adhesive joint performance: Effect of filler type on fraction energy," Journal of Applied Polymer Science, vol. 31, no. 7, pp. 2275-2302, 1986.

[44] G. Socrates, Infrared and Raman Characteristic Group Frequencies: Tables and Charts, John Wiley \& Sons, Chichester, UK, 2001. 

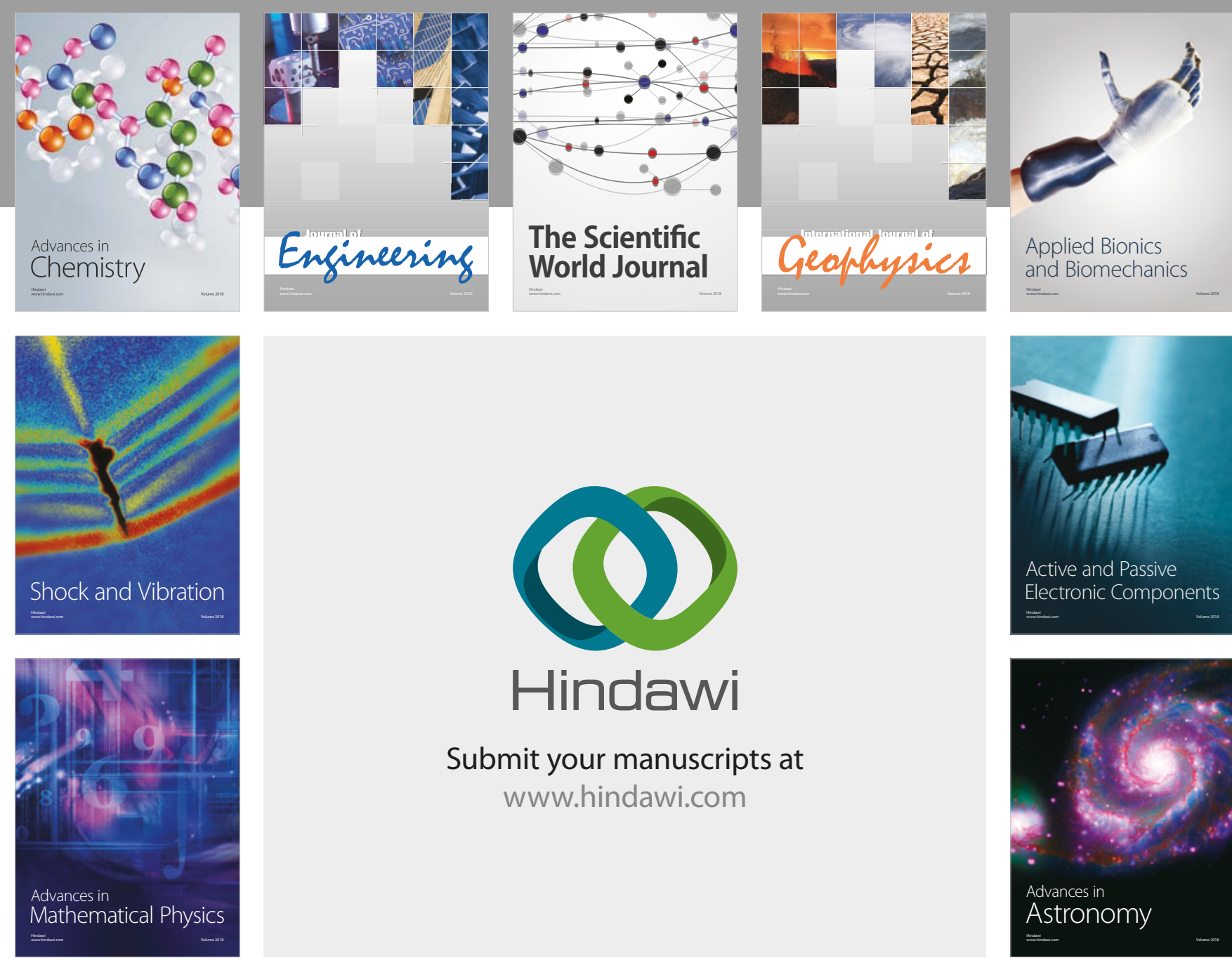

Submit your manuscripts at

www.hindawi.com

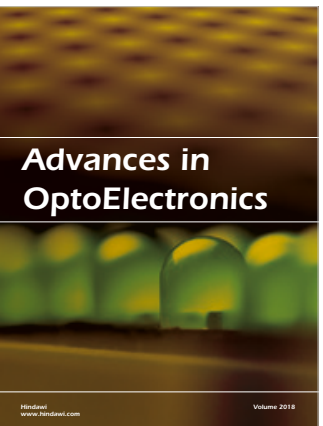

\section{Rotcting Machinery}
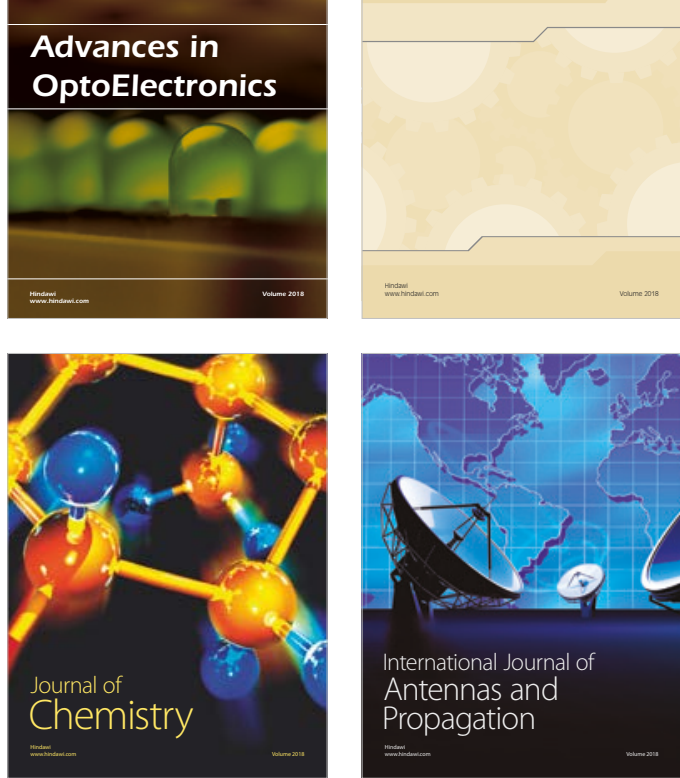

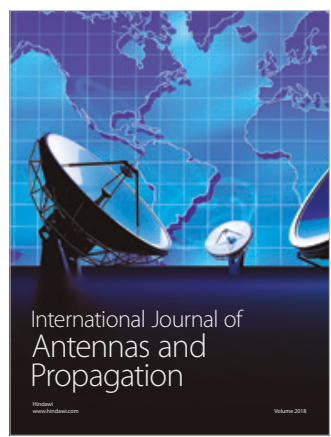

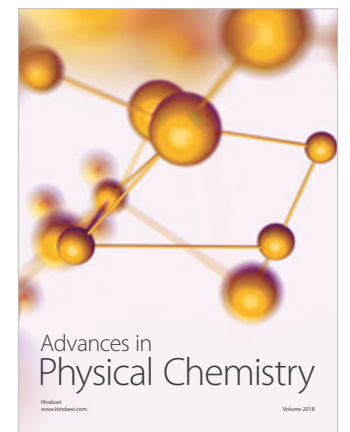

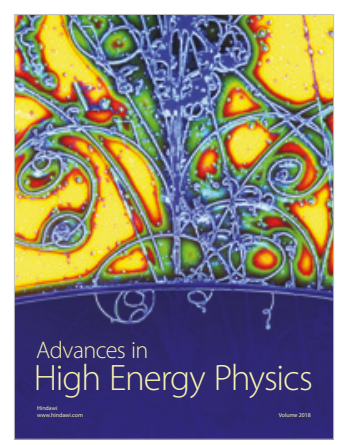

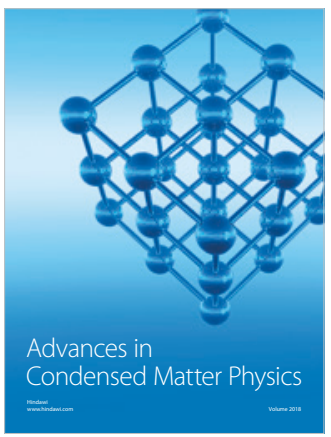

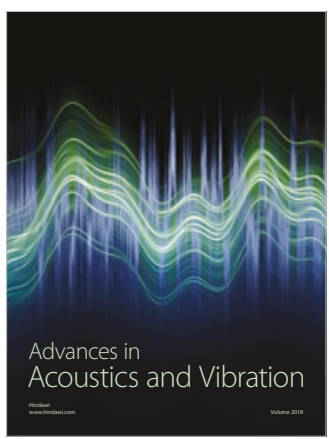

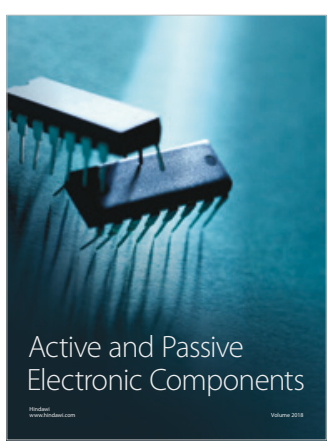
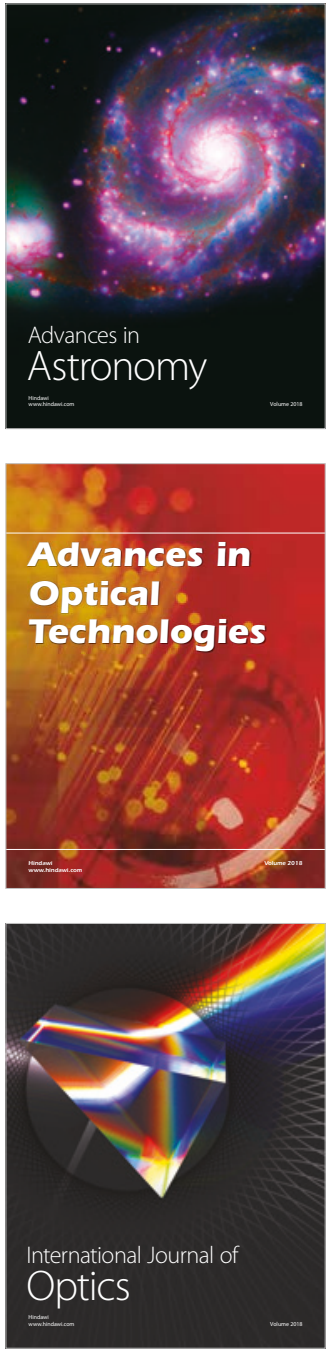